\title{
Correlations Between METAVIR Staging, the Viral Load and Alanine Aminotransferase Levels in Patients with Chronic Hepatitis C, Before and after 12 Weeks of Antiviral Treatment
}

\begin{abstract}
NICOLETA CRACIUN CIORBA1, ILIE MARIUS CIORBA2*, ION CLAUDIU PUIAC ${ }^{3}$, LIGIA ARIANA BANCU ${ }^{1}$
${ }^{1}$ Mures County Emergency Clinical Hospital, $1^{\text {st }}$ Department of Internal Medicine, 50 Dr. Gh. Marinescu Str. , 540136, Tirgu Mures, Romania

${ }^{2}$ Mures County Emergency Clinical Hospital, Department of Gastroenterology, 50 Dr. Gh. Marinescu Str., 540136, Tirgu Mures, Romania

3Mures County Emergency Clinical Hospital, Department of Intensive Care, 50 Dr. Gh. Marinescu Str., 540136, Tirgu Mures, Romania

The World Health Organization (WHO) estimates that 170 million individuals worldwide are infected with hepatitis C virus (HCV). The aim of study was to evaluate possible correlations between METAVIR staging, the viral loads and alanine aminotransferase (ALT) levels in patients with chronic hepatitis $C$, before and after 12 weeks of treatment with PegInterferon $\alpha 2 \mathrm{a} / \alpha 2 \mathrm{~b}$ and Ribavirin. 93 consecutive patients with hepatitis $C$, were included in this study. The parameters followed were age, sex, Metavir histologic staging at the start of the treatment, hepatitis C virus ribonucleic acid (HCV-RNA) and ALT at start and after 12 weeks of treatment, as well as alcohol intake. The study group was composed by 58 women and 35 men, with a mean age of $44.47 \pm 11.17$ years. At the beginning of the treatment, the mean value of HCV-RNA was $1327163 \pm 145001 \mathrm{UI} / \mathrm{mL}$, with a $\mathrm{Cl}_{95 \%}=1327163 \pm 287986.36 \mathrm{UI} / \mathrm{mL}$, and the mean value for ALT was $112.7124 \pm 68.7403 \mathrm{U} / \mathrm{l}$. After 12 weeks of therapy, significant differences were found concerning both HCV-RNA and ALT values. HCV-RNA lowered to a mean value of $457.3978 \pm 402.653(p<0.0001)$, while ALT lowered to a mean value of $37.90 \pm 16.43 \mathrm{U} / \mathrm{l}(p<0.0001)$. Neither the initial HCV-RNA nor ALT values had any correlations with the METAVIR histological staging of the fibrosis. Initial ALT was higher in those with alcohol intake ( $p=0.000048)$. The ALT values instead, after 3 months of treatment, decreased significantly $(p<0.0001)$, did correlate with the METAVIR groups $(p=0.0019)$. The evolutionary stage of fibrosis didn't correlate with gender of the patients or initial values of the HCV-RNA or ALT. There was no correlation between the age/gender of the patients and the determined METAVIR score.
\end{abstract}

Keywords: METAVIR staging, HCV RNA, ALT, PegInterferon, Ribavirin

The World Health Organization (WHO) estimates 170 million individuals worldwide are infected with hepatitis $C$ virus (HCV). However, the prevalence of HCV infection varies throughout the world. For example, in 2000, Frank et al reported that Egypt has the highest number of reported infections, largely attributed to the use of contaminated parenteral antischistosomal therapy [1]. This has led to a mean prevalence of $\mathrm{HCV}$ antibodies in persons in Egypt of $22 \%$. RNA-dependent RNA polymerase, an enzyme critical in HCV replication, lacks proofreading capabilities and generates a large number of mutant viruses known as quasispecies [2,3]. These represent minor molecular variations with only $1-2 \%$ nucleotide heterogeneity. $\mathrm{HCV}$ quasispecies pose a major challenge to immune-mediated control of HCV and may explain the variable clinical course and the difficulties in vaccine development. In most infected people, viremia persists and is accompanied by variable degrees of hepatic inflammation and fibrosis. Findings from studies suggest at least $50 \%$ of hepatocytes may be infected with HCV in patients with chronic hepatitis C $[4,5]$.

Histological Findings: Lymphocytic infiltration, moderate degrees of inflammation and necrosis, and portal or bridging fibrosis are noted. Regenerative nodules are seen in patients with cirrhosis. Some patients also may have findings indicative of HCC. Most pathologists give separate measurements of disease activity (grade) and fibrosis (stage). Many trials use the Ishak (6-point scale) and Knodell histological activity index (18-point score); both are useful for assessing improvements in histology findings in studies but are impractical for clinical use because of interobserver disagreement. The METAVIR score was developed by the French METAVIR Cooperative Study Group and reported by Bedossa and Poynard in 1996.The METAVIR score helps interpret a liver biopsy. The fibrosis is graded on a 5-point scale from 0 to 4 . The activity, which is the amount of inflammation (specifically, the intensity of necro-inflammatory lesions), is graded on a 4-point scale from $A 0$ to $A 3$. [6,7] Fibrosis score: $F 0=$ no fibrosis; $F 1=$ portal fibrosis without septa; $F 2=$ portal fibrosis with few septa; F3 = numerous septa without cirrhosis; F4 = cirrhosis. Activity score: $\mathrm{A} 0$ = no activity; $\mathrm{Al}=$ mild activity; $\mathrm{A} 2$ = moderate activity; $\mathrm{A} 3$ = severe activity

Aim of study was to evaluate possible correlations between METAVIR staging, the viral loads and ALT levels in patients with chronic hepatitis C, before and after 12 weeks of treatment with standard doses of either Peginterferon $\alpha 2 \mathrm{a}(180 \mu \mathrm{g} / \mathrm{week}) / \mathrm{or} \alpha 2 \mathrm{~b}(1.5 \mu \mathrm{g} / \mathrm{kgc} /$ week) plus Ribavirin in standard doses (1g/day under $75 \mathrm{~kg}$ or $1.2 \mathrm{~g} /$ day at more than $75 \mathrm{~kg}$ body weight). 


\section{Experimental part}

Material and methods

93 consecutive patients with hepatitis $C$, who were treated in the $2^{\text {nd }}$ Department of Internal Medicine at the Emergency County Hospital Mures in the last three years, were included in this study. The parameters followed, were age, sex, Metavir histological staging at the start of treatment, quantitative HCV-RNA at start and after 12 weeks of treatment, and the levels of ALT at the same points. We also made correlations with alcohol intake. The methods used for evaluation of the parameters were: Realtime-PCR for HCV RNA, with detection limit of $15 \mathrm{IU} / \mathrm{mL}$, standardized kinetic method without pyridoxal phosphate for ALT, with detection limit of $5 \mathrm{U} / \mathrm{L}$. METAVIR histological staging was performed by liver biopsy, using 2-2.5 cm of liver tissue, fixed in formalin, then stained with hematoxylineosin or using special stains. The statistical methods used in order to assess possible correlations between these parameters in our study were: descriptive statistics, F-test two samples for variances, Studentt-test, and simple linear correlation. All tests and graphics were computed using Microsoft Office Excel 2010, and Statsoft Statistica for Windows 8.0.

\section{Results and discussions}

The studied group was composed by 58 women and 35 men, with a mean age of $44.47 \pm 11.17$ years. Using the METAVIR score the patients were distributed in several groups. The majority of patients were in stages A2F2 and A2F3 according to METAVIR staging (fig. 1).

Descriptive statistics found a mean value of 1327163 $\mathrm{UI} / \mathrm{ml}$, with a standard error of $\pm 145001 \mathrm{UI} / \mathrm{mL}$ $\left(\mathrm{Cl}_{95 \%}=1327163 \pm 287986.36 \mathrm{UI} / \mathrm{mL}\right.$ ) for HCV-RNA (lower detectable value being $15 \mathrm{IU} / \mathrm{mL}$ ) and of $112.7124 \pm$ $68.74033 \mathrm{U} / \mathrm{L}$ for ALT (normal standard value $40 \mathrm{U} / \mathrm{L}$ ), before treatment. Comparing the values before treatment with those detected after 12 weeks of antiviral therapy, significant differences were found concerning both $\mathrm{HCV}$ RNA and ALT values. HCV-RNA lowered to a mean value of

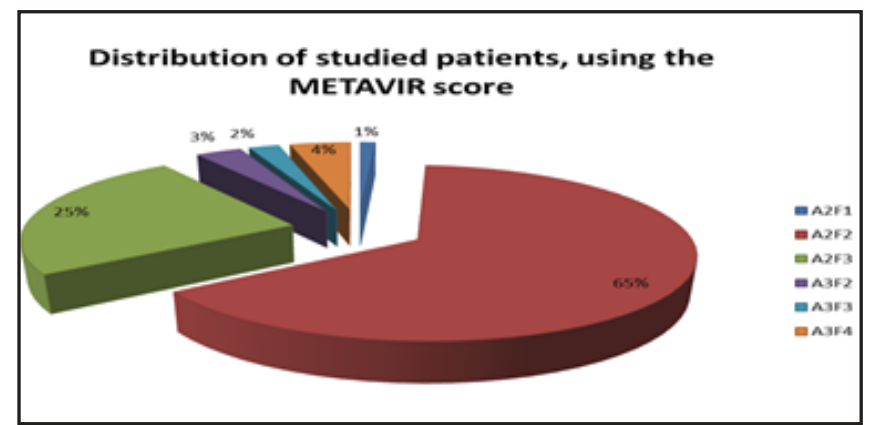

Fig. 1. The numeric distribution of the patients using the METAVIR score

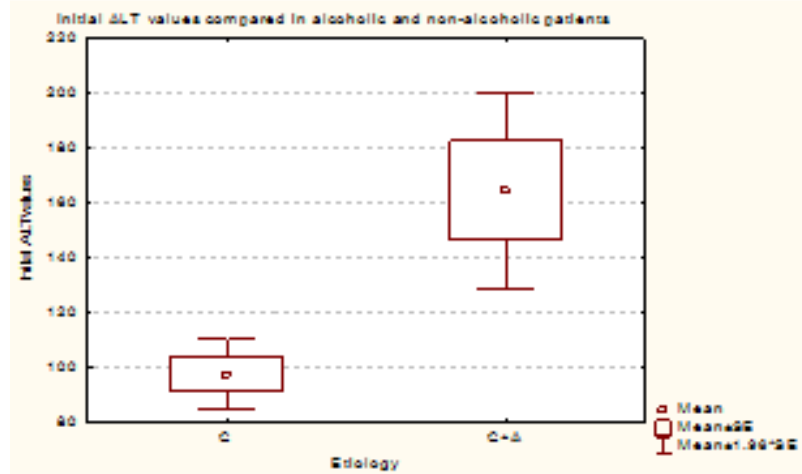

Fig. 3. Initial ALT values in alcoholic and non-alcoholic patients
$457.3978 \pm 402.653(p<0.0001)$, in 80 cases being undetectable, while ALT fell to a mean value of $37.90 \pm$ $16.43 \mathrm{U} / \mathrm{L}(p<0.0001)$, in 54 cases being under $40 \mathrm{U} / \mathrm{L}$.

After the correlations we made, the most important results were:

-No significant correlation could be made between the age of the patients and the initial HCV-RNA values $\left(R^{2}=0.0019\right)$.

- No significant differences were found between gender and HCV RNA values $(p=0.416)$.

- No statistical significant correlation could be established between the age of the patients and initial ALT values $\left(R^{2}=0.0011\right)$.

- In male patients the ALT values were significantly increased $(p=0.019)$. This result has to be interpreted in corroboration with HCV-RNA impact on ALT.

- There was no correlation between the initial values of ALT and HCV-RNA ( $R^{2}=0.0164$ ) (fig. 2).

-As a next step we examined the alcohol consumption, as the possible secondary factor. The incidence of an over $20 \mathrm{mg} /$ day alcohol ingestion was: in males: $45.71 \%$, in females: $8.77 \%$

-The initial ALT values were significantly higher in those with an over $20 \mathrm{mg} /$ day alcohol consumption $(p=0.000048)$ (fig. 3).

-After 3 months of treatment and no alcohol ingestion, the ALT values decreased (fig. 4).

Using METAVIR staging, we determined the correlations between the grade of fibrosis and HCV-RNA and ALT respectively, at start and after 12 weeks of treatment.

-The HCV-RNA mean values, before and after the 12 week treatment, hadn'tshow any significant variability with the METAVIR histological staging of the fibrosis $\left(p_{\text {inipRNA }}=0.679 ; p_{3 \text { menthRNA }}=0.99 ;\right)$ (fig. 5)

-The variance of the mean ALT values wasn't significant at the beginning of the study, but after 3 months of treatment, the variance proved to be highly significant $\left(p_{\text {initaLT }}=0.503 ; p_{3 \text { monthALT }}=0.0019\right)($ fig. 6$)$

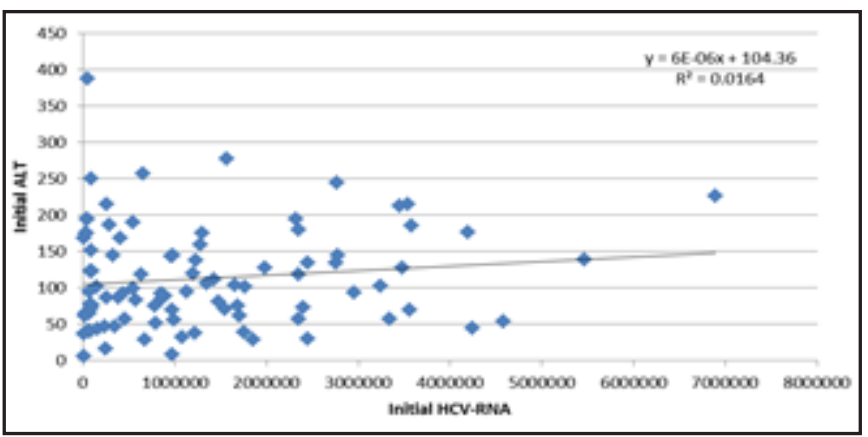

Fig. 2. Initial HCV-RNA values correlated with initial ALT values

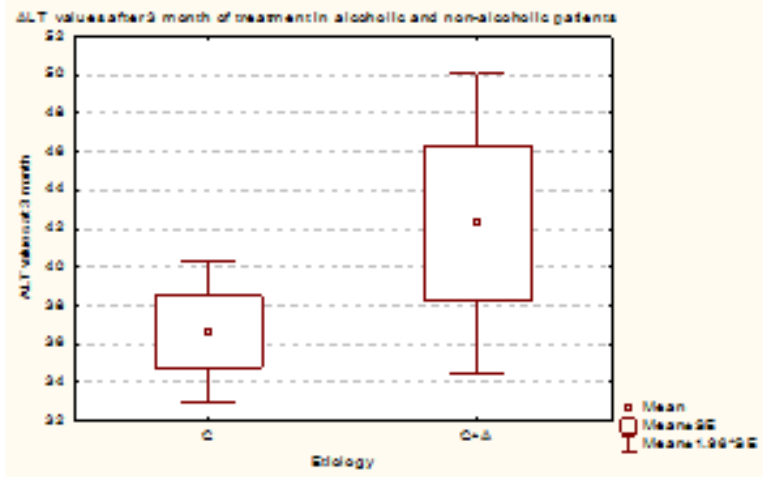

Fig. 4. ALT values after 3 month of treatment in alcoholic (most of them have abbandoned the alcohol consumption) and nonalcoholic patients. 

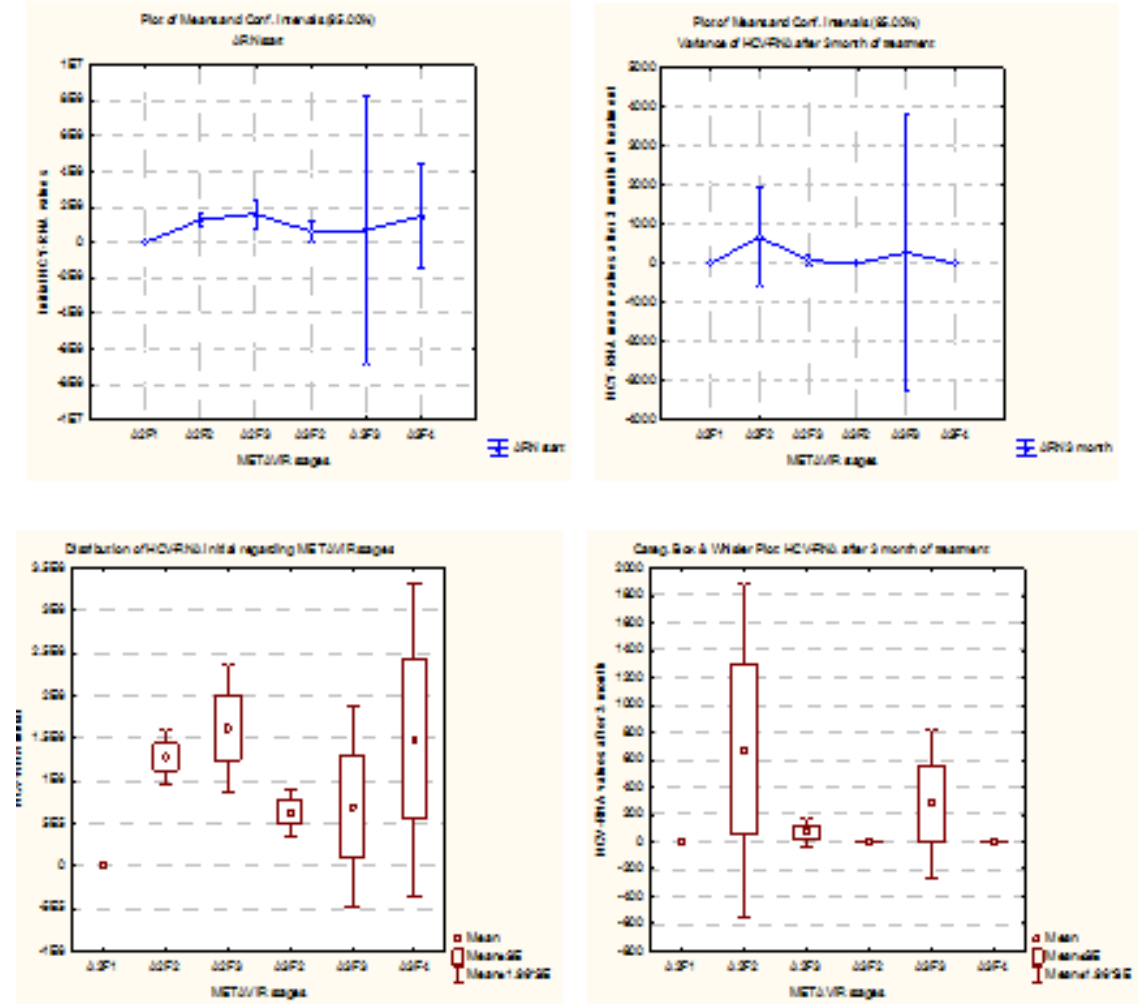

Fig. 5. Variance of HCV-RNA mean values before and after 3 months of treatment
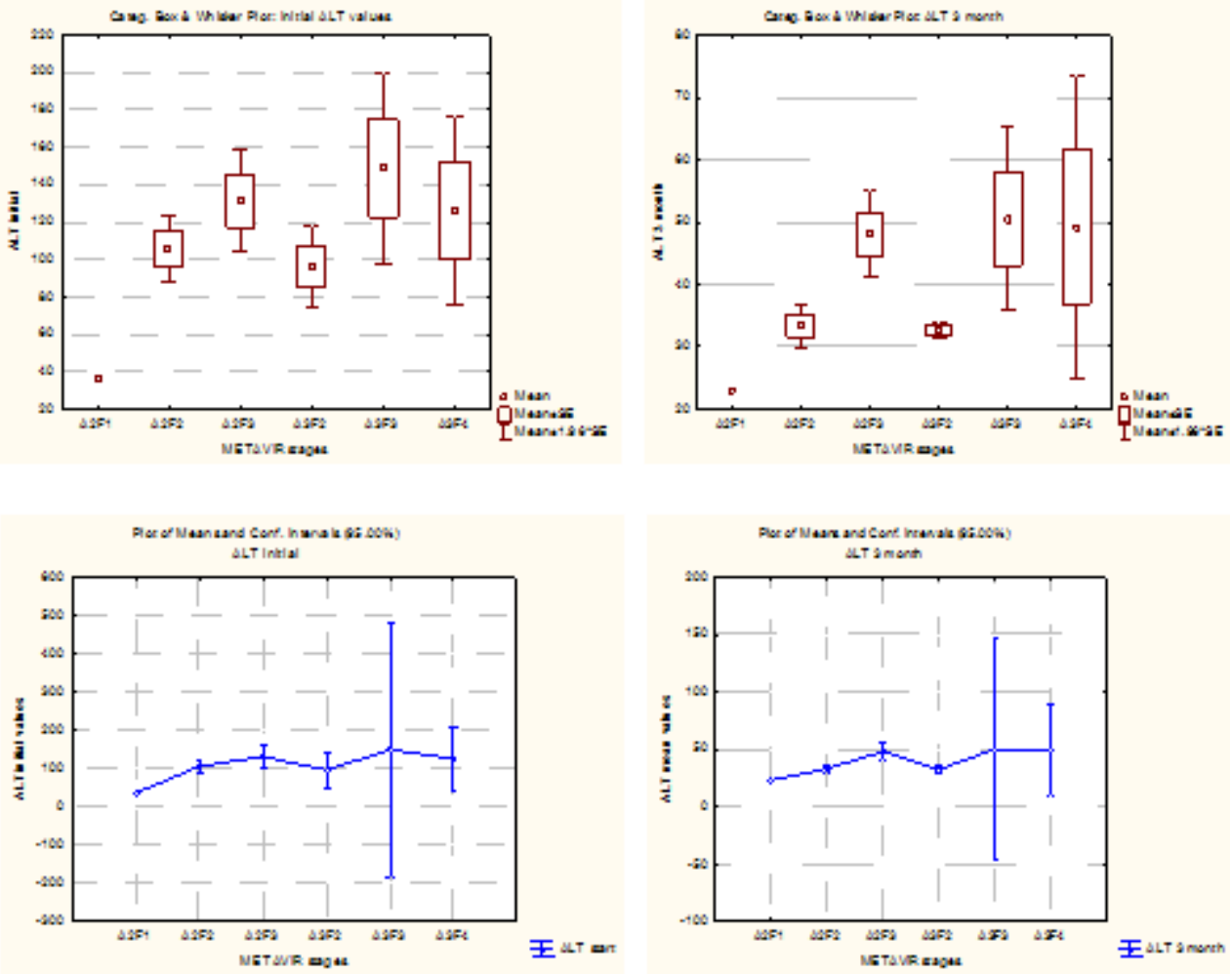

Fig. 6. Variance of ALT mean values before and after 3 month of treatment

-After 12 weeks of treatment, the values of HCV-RNA were significantly decreasing $(p<0.0001$ ) (fig. 7)

-The ALT values instead, after 3 months of treatment, decreased significantly $(p<0.0001)$ (fig. 8), and the variance of the ALT mean values correlate with the METAVIR groups $(p=0.0019)$ (fig. 11)

-No correlation could be made between the initial values of HCV-RNA and ALT(R=0.13). After 3 months of treatment, we managed to find a moderate positive correlation between these values ( $R=0.26$, correlations are significant at $p<.05000)$ (fig. 9 and 10).

Treatment with Peginterferon plus ribavirin, for 48 weeks is recommended for patients infected with HCV genotype

1, which represents the most common variant in Europe, and the majority in our country. Early virological response (EVR) analyzed after 12 weeks of treatment, defined as decrease of viral load $\geq 2$ log or undetectable HCV RNA. [8] Comparing our results with other studies, we reached comparable results, showing no correlation between the grade of fibrosis and EVR. The time to the first undetectable HCV RNA level is associated with the probability of virologic relapse after the end of treatment. EVR at 12 weeks is a good predictor for sustained virologic response. Thus, HCV RNA kinetics has strong predictive value $[9,10]$.

Lock et al, in a retrospective study on 126 pts with chronic viral hepatitis $C$ concluded that there was no 


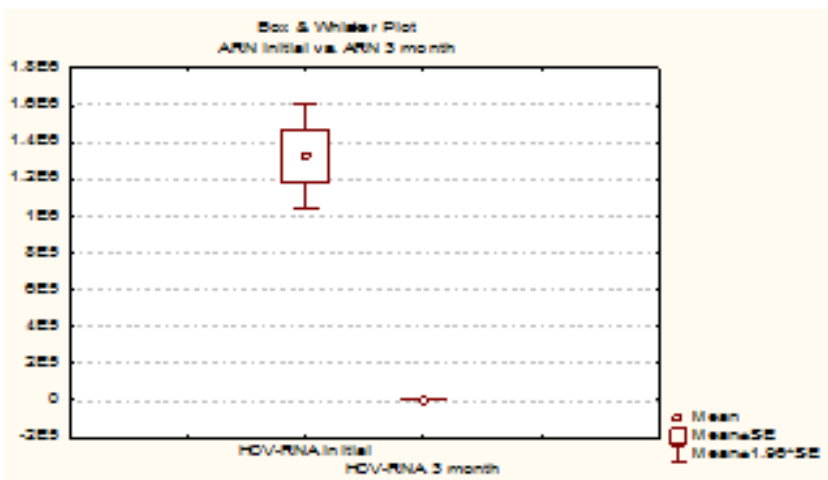

Fig. 7. Decrease of the HCV-RNA values after 3 month of treatment

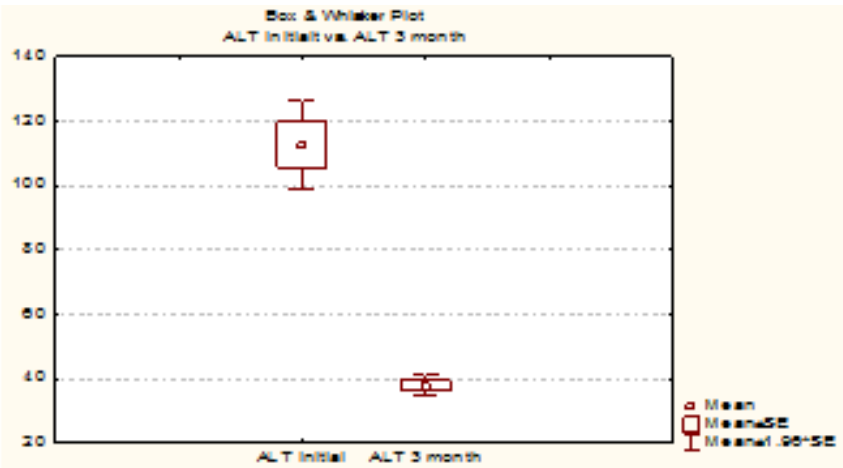

Fig. 8. Decrease of the ALT values after 3 month of treatment (and no alcohol ingestion)

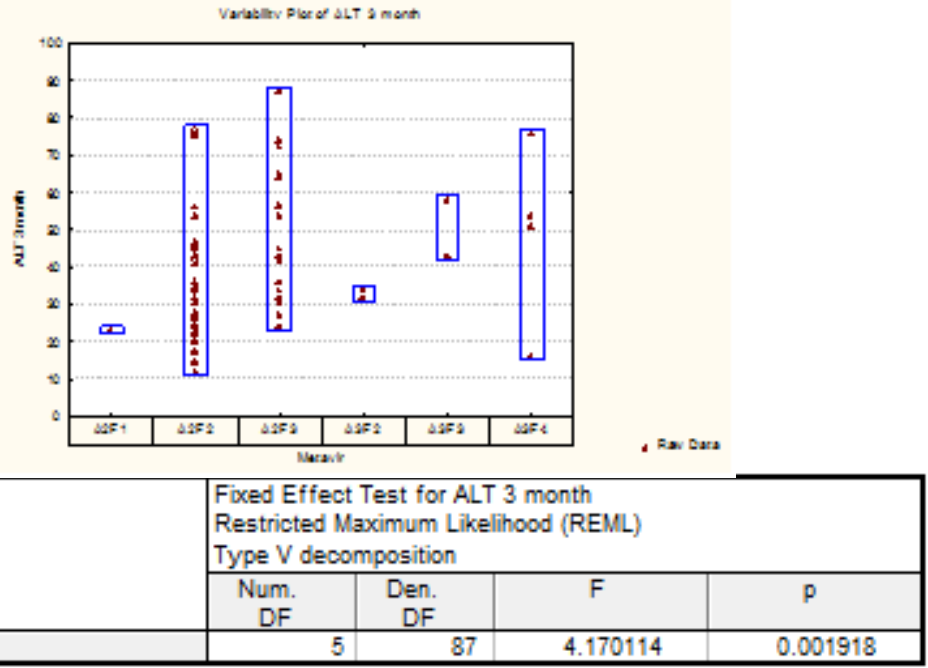

Fig. 11. Variability of ALT after 3 month of treatment vs. METAVIR groups

\begin{tabular}{|c|c|c|c|c|}
\hline \multirow[b]{2}{*}{ Effect } & \multicolumn{4}{|c|}{$\begin{array}{l}\text { Fixed Effect Test for ALT } 3 \text { month } \\
\text { Restricted Maximum Likelihood (REML) } \\
\text { Type V decomposition }\end{array}$} \\
\hline & $\begin{array}{l}\text { Num. } \\
\text { DF }\end{array}$ & $\begin{array}{c}\text { Den. } \\
\text { DF }\end{array}$ & $F$ & $p$ \\
\hline Metavir & 5 & 87 & 4.170114 & 0.001918 \\
\hline
\end{tabular}

association between inflammation or fibrosis and serum viral load. Inflammatory grading showed a moderate but significant correlation with ALT ( $p \leq 0.001$ ), whereas staging of fibrosis did not correlate with ALT. There was no association between grading or staging and serum viral load. Aminotransferases as surrogate markers reflectmore or less the histological inflammatory activity but do not allow any estimation of the extent of fibrosis. Some patients may have a high inflammatory activity with low aminotransferases or high aminotransferases with low inflammatory activity. Virological parameters such as HCV genotype or viral load do not allow an estimation of histological findings. If prior to treatment of chronic hepatitis $C$ liver biopsy is omitted and the decision for treatment depends solely on surrogate markers, considerable misjudgment of the actual status of liver inflammation or fibrosis may result [11].

Ticehurst et al, analyzed the baseline characteristics of 2472 HCV infected patients and concluded that increasing
HCV RNA was correlated with with higher fibrosis and necrosis- inflammation scores [12].

Factors associated with a smaller decrease in the HCV RNA level are in a study made by Hoofnagle et al, African American race, higher initial HCV RNA level, more severe hepatic fibrosis, and higher body weight [13-17].

Akkaya et al, in a study on 36 pts, also concluded that ALT levels correlate with duration of HCV infection, and histologic activity index, reflecting alterations in the liver tissue [1].

In our study we could not estimate the duration of the infection, this could be one reason for different results comparing with the last three mentioned studies.

\section{Conclusions}

The evolutionary stage of fibrosis didn't correlate with gender of the patients or initial values of the HCV-RNA or ALT. We found no correlation between the age of the patients and the determined METAVIR score. 
Initial values of ALT are positively correlated with gender, showing higher values in men. We believe that these results are given by increased alcohol consumption in this group.

The positive correlation between ALT after 3 months, and the METAVIR score, shows us a possible better response to the treatment in patients with lower stage of fibrosis. Despite the increased initial values of ALT in all groups, ALT decreases more in those with less severe fibrosis.

Correlation between HCV-RNA and ALT could not be considered significant, because of the HCV-RNA undetectable value measured in numerous cases after 3 month of treatment. The absence of correlation between the initial values of HCV-ARN, and ALT, suggests that the degree of the fibrosis, and cellular destruction caused by viral infection is not directly related to viral replication, and the evolution of fibrosis also involves other factors and mechanisms.

\section{Abreviations}

$\mathrm{ALT}=$ alanine aminotransferase

HCV RNA = hepatitis $C$ virus ribonucleic acid

$\mathrm{HCV}=$ hepatitis $\mathrm{C}$ virus

$\mathrm{HCC}=$ hepatocellular carcinoma

\section{References}

1.AKKAYA, O., KIYICI, M., YLMAZ, Y., ULUKAYA, E., YERCI, O. World J Gastroentero., 13, no. 41, 2007, p. 5481.

2.FLAMM, S.L., JAMA, 289, no. 18, 2003, p. 2413.

3. LINDSAY, K.L., HOOFNAGLE, J.H., Cecil Textbook of Medicine, 22nd edition, vol. 1, editors Goldman L, Bennett J C, Saunders, Philadelphia, 2004, p. 917.
4.DIENSTAG, J .L., MANDELL, D., BENNETT, J.E. Principles and Practice of Infectious Diseases, 6th Edition, vol. 1, Philadelphia Elsevier Churchill, Edited by Gerald L. Mandell, John E. Bennett, Raphael Dolin, Livingstone, 2005, p. 1441.

5.GHANY, M.G., Hepatology, 49, 2009, p. 1335.

6.BEDOSSA, P., POYNARD, T. Hepatology, 24, no. 2, 1996, p. 289.

7.HICKMAN, I.J ., CLOUSTON, A.D., MACDONALD, G.A., C Gut, 51, 2002, p. 89.

8.McHUTCHINSON, J., LAWITZ, E.J., SHIFMAN, M., MUIR, A., N Eng J Med, 361, no. 6, 2009, p. 580.

9.BERAK, H., KOLAKOWSKA-RZADZKA, A., WASILIEWSKI, M. Przegl Epidemiol., 60, no. 4, 2006, p. 673.

10.MAYLIN, S., MARTINOL-PEIGNOUX, M., MOUCARI, R., BOYER, N., Gastroenterology, 135, nr. 3, 2008, p. 821.

11.LOCKG, K., HAUERS, G., Med Klin, 95, no. 11, 2000, p. 603.

12.TICEHURST, J.R., HAMZEH, F.M., THOMAS, D.L., J Clin Microbiol., 45, no. 8, 2007, p. 2426.

13.HOOFNAGLE, J.H., WAHED, A.S., BROWN, R.S., HOWELL, C.D., BELLE, S.H., J Infect Dis., 199, no. 8, 2009, p. 1112.

14.GHEORGHE, D.N., RUSUS, D., HERASCU, E., POPESCU, D.M., SURLIN, P., ROGOVEANU, I., Rev. Chim.(Bucharest), 68, no. 6, 2017, p. 1252.

15.DROCHIOI, A.S., MORARU, D.C., DROCHIOI, I.C., IORGA, M., CRAUCIUC, E., Rev. Chim.(Bucharest), 69, no. 8, 2018, p. 2025.

16.COLDEA, L., GROSU, F., PINTEA, A.L., CERNUSCA MITARIU, S.I., GRIGORE, N., COMANEANU, R.M., ROMAN FILIP, C., Rev. Chim. (Bucharest), 68, no. 9, p. 2147.

17.FRANK, C., MOHAMED, M.K., STRICKLAND, G.T., LAVANCHY, D., ARTHUR, R.R., MAGDER, L.S., Lancet, 355, no. 9207, 2000, p. 887.

$\overline{\text { Manuscript received: } 22.01 .2019}$ 